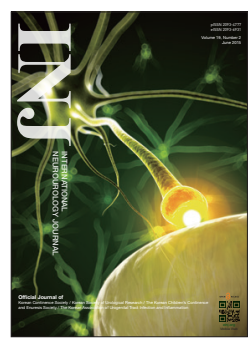

\title{
Intravesical Sodium Chondroitin Sulphate to Treat Overactive Bladder: Preliminary Result
}

\author{
Lokman Irkilata ${ }^{1}$, Mustafa Aydin ${ }^{1}$, Hasan Riza Aydin ${ }^{1}$, Hüseyin Cihan Demirel ${ }^{1}$, Mustafa Kadihasanoglu ${ }^{2}$, \\ Mustafa Kemal Atilla \\ ${ }^{1}$ Department of Urology, Samsun Training and Research Hospital, Samsun, Turkey \\ ${ }^{2}$ Department of Urology, Istanbul Training and Research Hospital, Istanbul, Turkey
}

\begin{abstract}
Purpose: This study aimed to verify the efficacy and safety of intravesical treatment with sodium chondroitin sulfate (CS) in patients with overactive bladder $(\mathrm{OAB})$ who are refractory to previous antimuscarinic treatment.

Methods: This study was performed between June 2012 and January 2015 and included 31 consecutive women (mean age, $42.10 \pm 7.34$ years) with $\mathrm{OAB}$ who had been previously treated with two types of antimuscarinic drugs. The results of gynecologic and cystoscopic examinations were normal, and $\mathrm{OAB}$ comorbidity was absent. Treatment with intravesical instillations containing $40 \mathrm{~mL}$ CS $(0.2 \% ; 2 \mathrm{mg} / \mathrm{mL})$ was administered for 6 weeks; after weekly treatments, monthly treatments were administered. The OAB-validated $8(\mathrm{OAB}-\mathrm{V} 8)$ symptom scores, nocturia, frequency, urgency, urge incontinence, and urinary volumes measured by uroflowmetry were evaluated for all the patients. The values obtained before the treatment were statistically compared with those obtained six months after the treatment.

Results: The duration of the symptoms was $18.36 \pm 6.19$ months. A statistically significant improvement of the patients' conditions was observed in terms of the OAB-V8 symptom scores, nocturia, frequency, urgency, urge incontinence, and urinary volumes measured by uroflowmetry after the treatment.

Conclusions: Despite the limitations of this study, the outcomes confirmed that CS therapy is safe and effective for the treatment of $\mathrm{OAB}$.
\end{abstract}

Keywords: Chondroitin Sulfates; Administration Intravesical; Urinary Bladder, Overactive

- Conflict of Interest: No potential conflict of interest relevant to this article was reported.

\section{INTRODUCTION}

Overactive bladder $(\mathrm{OAB})$ syndrome is defined as urinary urgency, usually accompanied by frequency and nocturia, with or without urgency urinary incontinence, in the absence of urinary tract infection or other obvious pathology [1]. The incidence of $\mathrm{OAB}$ is $12 \%-17 \%$, and the prevalence is $53.1 \%$ [2-5]. It is estimated that $50-100$ million people have OAB [6]. Idio- pathic detrusor overactivity is the common cause of OAB. However, detrusor overactivity is a urodynamic finding, while $\mathrm{OAB}$ is a symptomatic diagnosis [7]. Detrusor overactivity can be neurogenic or myogenic whereas $\mathrm{OAB}$ is idiopathic. Chronic OAB symptoms significantly affect patient's quality of life, but its objective clinical and histologic findings have not been determined [8-11]. In addition, the similarity in symptoms between $\mathrm{OAB}$ and interstitial cystitis further makes a definitive
Corresponding author: Lokman Irkilata (i) http://orcid.org/0000-0002-0141-8199 Department of Urology, Samsun Training and Research Hospital, Fevzi Çakmak Mahallesi, Altın Yunus Soakak, Liva Park Sitesi, B-2 Blok Ilkadım, Samsun, Turkey E-mail: irkilatamd@gmail.com / Tel: +90-533-715-3627 / Fax: +90-362-277-8569 Submitted: March 13, 2015 / Accepted after revision: May 11, 2015
This is an Open Access article distributed under the terms of the Creative Commons Attribution Non-Commercial License (http://creativecommons.org/licenses/by-nc/3.0/) which permits unrestricted non-commercial use, distribution, and reproduction in any medium, provided the original work is properly cited. 
diagnosis difficult. First-line pharmacological treatment comprises antimuscarinic agents, the use of which may be limited owing to their tolerability, efficacy, and long-term compliance [7]. Advances in elucidating the pathophysiology of $\mathrm{OAB}$ and alternative targets for pharmacological therapy have led to the development of newer agents to manage this condition. One such agent is sodium chondroitin sulfate (CS), a natural polymer of a disaccharide composed of a chain of glucuronic acid and $\mathrm{N}$-acetyl glucosamine sulfated either in the 4 or 6 position and is present naturally in the human body [12]. Glucosamine sulfate is the main component of the glycosaminoglycan layer, which protects urinary epithelium from toxic substances [13]. This study evaluated, retrospectively, the efficacy of intravesical $80 \mathrm{mg} / 40 \mathrm{~mL}$ sodium CS (0.2\%) (neutral-PH, containing no preservatives or adjuvants) in patients with $\mathrm{OAB}$ who had no improvement in their symptoms even after the use of several antimuscarinics.

\section{MATERIALS AND METHODS}

This study originally included 33 consecutive patients who had normal gynecological functions, normal cystoscopic findings, and no disease underlying their $\mathrm{OAB}$ between June 2012 and January 2015. Patients with following conditions were excluded: who had stress or mixed incontinence with more than $100 \mathrm{~mL}$ residual urine, those with prolapse, underlying neurological disease, and intolerance to the first administration of intravesical treatment. Two patients could not tolerate the treatment and left the study; the study finally had 31 patients.
For diagnosis before treatment and follow-up after treatment, patients filled out the validated Turkish version of the OAB-validated 8 (OAB-V8) questionnaire (Table 1) [14,15]. The OAB-V8 comprises the first 8 questions of the OAB questionnaire $(\mathrm{OAB}-\mathrm{q})$ and has been translated into many languages. The OAB-q is recommended for use in screening and monitoring $\mathrm{OAB}$ [14-16].

Study participants had OAB with unresolved symptoms in spite of treatment with antimuscarinic agents (at least two active agents for at least 3 months but which had been discontinued for at least 1 month). Efficacy of intravesical sodium CS sulfate treatment was retrospectively evaluated in the patient group administered intravesical sodium CS.

Our treatment protocol included one application of 80 $\mathrm{mg} / 40 \mathrm{~mL}$ sodium CS $(0.2 \%)$ weekly for 6 weeks. One month after the last administration, patients were followed up. Before monthly treatment, patients were evaluated using OAB-V8 form for nocturia, frequency, and urgency, and uroflowmetry (UFM) also performed to determine the efficacy of treatment and whether or not the treatment had to be continued. OABV8 scores, nocturia, frequency, urgency, urge incontinence, and urine volumes in UFM before treatment were compared to those recorded 6 months after treatment.

IBM SPSS Statistics ver. 21.0 (IBM Co., Armonk, NY, USA) was used for statistical analysis. The Shapiro-Wilk test was used to assess normality of data. Results of descriptive analyses are given as mean \pm standard deviation, number (\%), and median (range). Statistical analyses for the patient group were performed using paired samples t-test and Wilcoxon paired sam-

Table 1. OAB-V8 questionnaire

\begin{tabular}{|c|c|c|c|c|c|c|}
\hline To what extent do the following cause discomfort? & Not at all & A little bit & Somewhat & Quite a bit & A great deal & A very great deal \\
\hline Frequent urination during the daytime hours? & 0 & 1 & 2 & 3 & 4 & 5 \\
\hline An uncomfortable urge to urinate? & 0 & 1 & 2 & 3 & 4 & 5 \\
\hline A sudden urge to urinate with little or no warning? & 0 & 1 & 2 & 3 & 4 & 5 \\
\hline Accidental loss of small amounts of urine? & 0 & 1 & 2 & 3 & 4 & 5 \\
\hline Night-time urination? & 0 & 1 & 2 & 3 & 4 & 5 \\
\hline Waking up at night because you have to urinate? & 0 & 1 & 2 & 3 & 4 & 5 \\
\hline An uncontrollable urge to urinate? & 0 & 1 & 2 & 3 & 4 & 5 \\
\hline Urine loss associated with a strong desire to urinate? & 0 & 1 & 2 & 3 & 4 & 5 \\
\hline \multicolumn{7}{|l|}{ Total score } \\
\hline OAB score $\mathrm{s}^{\mathrm{a})}$ & & & & & & \\
\hline
\end{tabular}

OAB, overactive bladder; OAB-V8, OAB-validated 8.

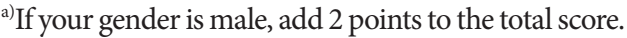


Table 2. Comparison of the study parameters before and after treatment $(n=31)$

\begin{tabular}{lccc}
\hline Parameter & Pretreatment & Posttreatment & P-value \\
\hline Nocturia, median (range) & $4(2-7)$ & $1(0-2)$ & $<0.001$ \\
frequency, median (range) & $8(7-10)$ & $5(5-7)$ & $<0.001$ \\
Urine volume $(\mathrm{mL})$, mean \pm SD & $306.26 \pm 56.11$ & $388.00 \pm 39.12$ & $<0.001$ \\
Urge incontinence, $\mathrm{n}(\%)$ & $21 / 31(67.7)$ & $2 / 31(6.5)$ & $<0.001$ \\
OAB symptom score, mean \pm SD & $20.55 \pm 4.77$ & $8.42 \pm 1.96$ & $<0.001$ \\
\hline
\end{tabular}

$\mathrm{SD}$, standard deviation; $\mathrm{OAB}$, overactive bladder.

ples test. P-values less than 0.05 were considered statistically significant.

\section{RESULTS}

All 33 patients were female with a mean age of $42.10 \pm 7.34$ years. Two patients were excluded owing to intolerance to the intravesical treatment; the study finally comprised 31 patients. Mean symptom duration was $18.36 \pm 6.19$ months. Duration of antimuscarinic agents use in these patients was found to be $11.67 \pm 4.40$ months (range 2-20 months). The antimuscarinic agents used were, in order of frequency, fesoterodine, solifenacin, propiverine hydrochloride, and trospium chloride. While urgency fully resolved in 29 patients (93.5\%), 2 patients did not show complete improvement but revealed some decrease in complaints. Table 2 showed nocturia, frequency, urine volume in UFM, urge incontinence, OAB symptom scores, before and after treatment. All parameters showed some improvement after treatment $(\mathrm{P}<0.001)$.

Although complete symptomatic relief of urgency or incontinence was not reported in two patients, some improvement in both symptoms was reported. Moreover, at the end of the 6th month, all 31 patients were satisfied with the outcome of therapy and stated that they wanted to continue treatment.

\section{DISCUSSION}

$\mathrm{OAB}$ is a widespread troublesome disorder known to have considerable impact on quality of life and to be underdiagnosed and undertreated by physicians. The pathophysiology of OAB has not been fully explained. Generally, it is thought that nonpreventable detrusor contractions play a role. The two classic theories about this condition are the myogenic theory and the neurogenic theory $[11,17]$. According to the neurogenic theory, changes in the central peripheral and local innervation of the bladder result in detrusor overactivity. The study by Chancellor and de Groat [11] focused on local innervations and showed that one of the causes of $\mathrm{OAB}$ may be the reflex to urinate as a result of over stimulation of unmyelinated C-afferent fibers. Therefore, the idea that intravesical treatment approaches may be effective against $\mathrm{OAB}$ is obvious, as in our study. The theories related to $\mathrm{OAB}$ pathophysiology form the basis of $\mathrm{OAB}$ treatment approaches. Patients who do not benefit from firstline treatments for $\mathrm{OAB}$, such as behavioral therapies, are recommended to choose second-line treatments such as antimuscarinic agents and $\beta$-3 adrenoceptor agonists such as mirabegron [18]. Currently, antimuscarinic agents are the most commonly used first-choice drugs for the treatment of OAB, although they have been associated with troublesome side effects and may lack efficacy. In addition, compliance and persistence with treatment remains a problem with antimuscarinic agents [7]. In situations where second-line treatments are refractory or are not tolerated, third-line treatments are recommended [18]. Third-line treatments include onabotulinum toxin A therapy, peripheral tibial nerve stimulation, and neuromodulation. In addition to the invasive nature and infection risks of third-line treatments, the greatest disadvantages are increased postvoid residuals and lack of rapid recovery [18]. Intravesical chondroitin treatment does not carry the risks of third-line treatments for patients not responding to antimuscarinic agents. However, the need to administer the treatment over several months in the hospital environment may be a disadvantage.

The differential diagnosis between $\mathrm{OAB}$ and interstitial cystitis further complicates the treatment of OAB. Interstitial cystitis is a debilitating, chronic disease characterized by urinary urgency, frequency, and bladder and pelvic pain, which have a profoundly negative effect on quality of life [19]. Despite worldwide scientific studies and research, there remains little consensus on the etiology and effective treatment of interstitial cystitis. Hence, diagnosis is dependant on inclusive and exclusive clini- 
cal diagnostic criteria based on guidelines of the National Institute of Diabetes and Digestive and Kidney Diseases (NIDDK) [20]. When viewed from this aspect, interstitial cystitis remains a diagnosis of exclusion, with no cystoscopic or pathologic findings that can be used for a definitive diagnosis.

It has been suggested that strict application of NIDDK criteria would have resulted in misdiagnoses in more than $60 \%$ of patients who were regarded by researchers as definitely or likely to have interstitial cystitis [10]. This means that patients who present with urgency, frequency, and nocturia potentially could be diagnosed with either $\mathrm{OAB}$ or interstitial cystitis. Therefore, it is not easy to differentiate $\mathrm{OAB}$ from interstitial cystitis, and different treatment modalities can be used without a differential diagnosis. Gauruder-Burmester et al. [21] determined that instillation of sodium CS for treatment of interstitial cystitis also is effective in treating overactive bladder based on the assumption that the glycosaminoglycan layer may be damaged in overactive bladder as well. They found that restoring the glycosaminoglycan layer with intravesical sodium CS improved symptoms in patients with OAB. In addition, they demonstrated that the symptom improvement observed after treatment with $0.2 \%$ sodium CS persists even after 24 months [22].

In spite of positive results obtained by Gauruder-Burmester et al. [21,22], CS is still not widely used for treatment of persistent $\mathrm{OAB}$.

Sodium CS treatment for overactive bladder is not sufficiently well reported. We employed intravesical sodium CS therapy for $\mathrm{OAB}$ treatment. However, as explained above, for refractory $\mathrm{OAB}$ patients, intravesical sodium CS treatment is a promising alternative to overcome the disadvantages of third-line treatment since it is reversible and has no serious complications; hence, it should be considered before using third-line treatment. Patients in this study were diagnosed with $\mathrm{OAB}$, had undergone treatment with different therapeutics, some of which they could not recall, and had been treated with at least two types of antimuscarinics. Patients with OAB are often administered antibiotics without appropriate indications. Patients refractory to antimuscarinics were treated with intravesical sodium CS. OAB symptom scores were $20.55 \pm 4.77$ before treatment and decreased to $8.42 \pm 1.96$ after treatment. Patients stated that their symptoms improved significantly. They reported subjectively that nocturia symptoms were no more bothersome and their sleep quality improved. Although some patients had been reluctant to participate in the study owing to invasive nature of therapy, all patients who completed the study were satisfied with the outcome and decided to continue therapy. Owing to the development of the glycosaminoglycan layer, instillation treatment with $0.2 \%$ sodium CS resulted in a sustained improvement or treatment of OAB symptoms [21,22].

Although intravesical sodium CS treatment for OAB had positive outcome, the fact that this study was not prospective or randomized presents major limitations. In addition, using OAB-q instead of OAB-V8 to evaluate treatment results in patients would have shown not only resolution of symptoms but also improvement in quality of life, making the results more valuable.

In conclusion, intravesical sodium CS treatment may be an effective and reliable alternative to third-line treatment for patients with $\mathrm{OAB}$ refractory to antimuscarinic agents or not well tolerated. In spite of the limitations stated above, results of this study are encouraging. However, additional randomized clinical trials are required to confirm these findings.

\section{ACKNOWLEDGEMENTS}

We gratefully acknowledge expert statistician Naci Murat for re-evaluating our study data.

\section{REFERENCES}

1. Abrams P, Cardozo L, Fall M, Griffiths D, Rosier P, Ulmsten U, et al. The standardisation of terminology of lower urinary tract function: report from the Standardisation Sub-committee of the International Continence Society. Neurourol Urodyn 2002;21:167-78.

2. Milsom I, Abrams P, Cardozo L, Roberts RG, Thuroff J, Wein AJ. How widespread are the symptoms of an overactive bladder and how are they managed? A population-based prevalence study. BJU Int 2001;87:760-6.

3. Stewart WF, Van Rooyen JB, Cundiff GW, Abrams P, Herzog AR, Corey R, et al. Prevalence and burden of overactive bladder in the United States. World J Urol 2003;20:327-36.

4. Yamanishi T, Chapple CR, Chess-Williams R. Which muscarinic receptor is important in the bladder? World J Urol 2001;19:299306.

5. Lapitan MC, Chye PL; Asia-Pacific Continence Advisory Board. The epidemiology of overactive bladder among females in Asia: a questionnaire survey. Int Urogynecol J Pelvic Floor Dysfunct 2001;12:226-31.

6. Miller JJ, Sand PK. Diagnosis and treatment of overactive bladder. Minerva Ginecol 2005;57:501-20. 
7. Jayarajan J, Radomski SB. Pharmacotherapy of overactive bladder in adults: a review of efficacy, tolerability, and quality of life. Res Rep Urol 2013;6:1-16.

8. Gimbel H, Zobbe V, Andersen BJ, Sorensen HC, Toftager-Larsen $\mathrm{K}$, Sidenius $\mathrm{K}$, et al. Lower urinary tract symptoms after total and subtotal hysterectomy: results of a randomized controlled trial. Int Urogynecol J Pelvic Floor Dysfunct 2005;16:257-62.

9. Curhan GC, Speizer FE, Hunter DJ, Curhan SG, Stampfer MJ. Epidemiology of interstitial cystitis: a population based study. J Urol 1999;161:549-52.

10. Hanno PM, Landis JR, Matthews-Cook Y, Kusek J, Nyberg L Jr. The diagnosis of interstitial cystitis revisited: lessons learned from the National Institutes of Health Interstitial Cystitis Database study. J Urol 1999161:553-7.

11. Chancellor MB, de Groat WC. Intravesical capsaicin and resiniferatoxin therapy: spicing up the ways to treat the overactive bladder. J Urol 1999;162:3-11.

12. Baeurle SA, Kiselev MG, Makarova ES, Nogovitsin EA. Effect of the counterion behavior on the frictional-compressive properties of chondroitin sulfate solutions. Polymer 2009; 50:1805-13.

13. Hurst RE. Structure, function, and pathology of proteoglycans and glycosaminoglycans in the urinary tract. World J Urol 1994;12:310.

14. Acquadro C, Kopp Z, Coyne KS, Corcos J, Tubaro A, Choo MS, et al. Translating overactive bladder questionnaires in 14 languages.
Urology 2006;67:536-40.

15. Tarcan T, Mangir N, Ozgur MO, Akbal C. OAB-V8 overactive bladder questionnaire validation study. Urology Bull 2012;21:113-6.

16. Oh SJ, Son H, Kim SW, Lee KS, Choo MS, Kim SO, et al. Psychometric properties of the Korean version of the overactive bladder questionnaire (OAB-q) in a Korean population. Int Neurourol J 2012;16:77-85.

17. Mostwin JL. Pathophysiology: the varieties of bladder overactivity. Urology 2002;60(5 Suppl 1):22-6.

18. Gormley EA, Lightner DJ, Burgio KL, Chai TC, Clemens JQ, Culkin DJ, et al. Diagnosis and treatment of overactive bladder (non-neurogenic) in adults: AUA/SUFU guideline. J Urol 2012;188(6 Suppl):2455-63.

19. Brinkmann OA, Hertle L. The pathogenesis of interstitial cystitis-many hypotheses, but etiology remains uncertain. Urologe A 2000;39:520-6.

20. Wilkins EG, Payne SR, Pead PJ, Moss ST, Maskell RM. Interstitial cystitis and the urethral syndrome: a possible answer. $\mathrm{Br} J$ Urol 1989;64:39-44.

21. Gauruder-Burmester A, Wildt B, Tunn R. Treatment of overactive bladder with sodium chondroitin sulphate. Zentralbl Gynakol 2006;128:336-40.

22. Gauruder-Burmester A, Popken G. Follow-up at 24 months after treatment of overactive bladder with $0.2 \%$ sodium chondroitin sulfate. Aktuelle Urol 2009;40:355-9. 